\title{
Regulation of Varicella-Zoster Virus Gene Expression in Human T Lymphocytes
}

\author{
L. P. PERERA, ${ }^{1 *}$ J. D. MOSCA, ${ }^{2}$ W. T. RUYECHAN, ${ }^{3}$ AND J. HAY ${ }^{1}$ \\ Departments of Microbiology ${ }^{1}$ and Biochemistry, ${ }^{3}$ Uniformed Services University of \\ the Health Sciences, Bethesda, Maryland 20814-4799, and Retrovirus Research \\ Laboratory, Henry M. Jackson Foundation, Rockville, Maryland 20852 ${ }^{2}$
}

Received 12 February 1992/Accepted 11 June 1992

\begin{abstract}
Varicella-zoster virus (VZV), a neurotropic alphaherpesvirus, is the etiologic agent of chicken pox and shingles (zoster) in humans. Using an in vitro transient expression assay, we have evaluated the ability of the putative immediate early VZV genes, ORF4, ORF61, and ORF62 (the analogs of the herpes simplex virus $\alpha_{27,}$ $\propto 0$, and $\alpha 4$ genes, respectively), to modulate the expression of VZV genes of different putative kinetic classes in a human $\mathrm{T}$ lymphocyte cell line. These cells are of the type in which VZV can be readily detected in the viremic phase of human infection. We present evidence to indicate that, in this system, the gene product of ORF62 (IE62) is a major regulatory protein in VZV and is capable of activating VZV genes of all putative kinetic classes. In addition, we demonstrate that the gene product of ORF4 and, unlike the apparent situation in Vero cells, the gene product of ORF61 may play an accessory regulatory role in synergizing the activation of VZV genes induced by the gene product of ORF62 in human T lymphocytes.
\end{abstract}

Varicella-zoster virus (VZV), a neurotropic alphaherpesvirus, is the etiologic agent of two distinct clinical syndromes: chicken pox (varicella) and shingles (zoster). Primary VZV infection results in chicken pox and is usually characterized by a self-limiting generalized exanthema that is highly contagious and commonly seen in children. Following primary chicken pox infection, the virus remains latent in dorsal or cranial root ganglia. In elderly or immunocompromised individuals, the reactivation of latent virus leads to shingles, a condition with painful vesicular lesions usually limited to a single dermatome.

VZV is an enveloped virus with a linear double-stranded DNA genome of approximately $125,000 \mathrm{bp}$ and a base composition of $46 \%$ guanine plus cytosine $(G+C)$. The complete nucleotide sequence of the VZV genome has been determined and predicts approximately 70 unique genes (7). By analogy to related sequences in herpes simplex virus (HSV) and by direct analyses, functions have been assigned to many of the viral gene products, although the majority of these still remain undefined $(24,29,35)$. Much progress has been made in functional analysis of HSV genes by generating specific mutations in the viral genome by exploiting its ability to undergo efficient homologous recombination (34). However, this approach has not been very fruitful in the study of VZV genes, since VZV has proven to be refractory to such genetic manipulations.

Although the expression of VZV genes appears to be temporally regulated (37), the inability to generate cell-free stocks of the highly cell-associated VZV with high titers has impeded the detailed analysis of VZV gene regulation. Nonetheless, putative kinetic classes have been defined for VZV genes on the basis of sequence homology and genetic topology to immediate-early (IE) $(\alpha)$, early $(\beta)$, and late $(\gamma)$ genes encoded by HSV type 1 (HSV-1) $(5,16,17)$. Three putative VZV IE genes which correspond to ICP0, ICP4, and ICP27 in the HSV system have been identified. These are open reading frames (ORFs) 61,62 , and 4 , respectively

\footnotetext{
${ }^{*}$ Corresponding author.
}

$(6,7,37)$. Although complementation studies of HSV ICP4 mutants with VZV ORF62 have confirmed functional similarities between these two proteins, there is at present no evidence to indicate any functional similarities between either VZV ORF61 and ICP0 or VZV ORF4 and ICP27 (8, $11,12,19)$.

However, in the area of gene regulation, significant differences between HSV and VZV exist. For example, VZV lacks a functional $\alpha$-trans-inducing factor (VP16 or Vmw65) gene which, in HSV-infected cells, is involved in transactivation of IE gene expression $(2,4,26,31,33)$. Thus, induction of IE genes of VZV during productive infection appears to be mediated by a different mechanism, and the factor(s) responsible for immediate-early gene induction in VZV remains undefined.

There is strong evidence to indicate the presence of VZV in circulating $\mathrm{T}$ lymphocytes during the viremic phase of human infection $(1,14,21,22,30,39)$, and as a first step toward understanding the transcriptional regulation of VZV genes in these cells, we have investigated the regulatory roles of ORF61, ORF62, and ORF4 in modulating the activity of VZV genes of different kinetic classes using an in vitro transient cotransfection system in human $\mathrm{T}$ lymphocytes. In this communication, we show that the gene product of ORF62 is a major regulatory protein of VZV and is capable of upregulating the expression of VZV genes of all three putative kinetic classes. In addition, we present evidence to implicate accessory regulatory roles for the gene products of ORF4 and ORF61 of VZV.

\section{MATERIALS AND METHODS}

Cell lines. A CD4-positive, continuous human $\mathrm{T}$ cell line, A3.01 (13), was obtained from the AIDS Research and Reference Reagent Program, National Institute of Allergy and Infectious Diseases, and was maintained in RPMI 1640 medium supplemented with $10 \%$ fetal calf serum. The cells were routinely screened for mycoplasma contamination. Vero cells were obtained from the American Type Culture 
Collection (Rockville, Md.) and grown in Opti-MEM medium (GIBCO-BRL) with $5 \%$ fetal calf serum.

Plasmid constructs. Recombinant plasmids were constructed by standard cloning procedures (25). The plasmids pGORF4, pGORF61, and pGi26 contain a single copy of ORF4, ORF61, and ORF62 of VZV, respectively, and are driven from their cognate promoters. Detailed descriptions of the construction of these plasmids have been published elsewhere $(11,18,27)$.

To create p4CAT, pGORF4 was restricted with NcoI and then treated with mung bean nuclease followed by digestion with BamHI. Following gel electrophoresis, a 3.6-kb fragment containing the promoter region of ORF4 was isolated. The coding region of the chloramphenicol acetyltransferase (CAT) gene was isolated from pCAT Basic (Promega) as follows: the pCAT Basic plasmid was linearized by being digested with PstI and then treated with mung bean nuclease. Next, pCAT Basic plasmid that had been linearized with Pst I was cut with Bam HI and subjected to agarose gel electrophoresis. A 1.7-kb fragment containing the coding region of the CAT gene was isolated, and this fragment was then ligated to the $3.6-\mathrm{kb}$ fragment containing the ORF4 promoter. In the resultant construct, p4CAT, the CAT gene is placed under the transcriptional control of the ORF4 promoter embedded in a segment extending from -2 to -888 relative to the initiator AUG codon of ORF4.

To create p61CAT, pGi26 was restricted with $N r u I$ and EcoRI followed by mung bean nuclease treatment to blunt the cut ends (in pGi26, the BglII-HpaI fragment from the Ellen strain of VZV contains an additional NruI site 605 bp downstream of the $N r u I$ site in the published DNA sequence of the Dumas strain [31a]). After agarose gel electrophoresis, a 4.4-kb fragment was isolated and recircularized by bluntend ligation with T4 DNA ligase. This construct was designated pGi26 $\Delta \mathrm{EN}$. The pGi26 $\Delta \mathrm{EN}$ lacks a functional ORF62, and only $760 \mathrm{bp}$ upstream of the terminator TGA codon of ORF62 is retained in this construct. The plasmid pGi26 $2 \mathrm{EN}$ was then digested with NcoI, and the ends were blunted with mung bean nuclease and then cut with BamHI. After agarose gel electrophoresis, a $4.1-\mathrm{kb}$ fragment was isolated. This fragment was ligated to a $1.7-\mathrm{kb}$ Bam HI-Pst Iragment (the PstI end blunted with mung bean nuclease) containing the coding region of the CAT gene as described earlier. The resultant construct was designated p61CAT. In p61CAT, the CAT gene is under the transcriptional control of the ORF61 promoter embedded within a segment extending from +65 to -1400 relative to the mRNA cap site of ORF61 (27).

The plasmid pgpIVCAT was constructed as follows. The segment extending from +63 to -363 (with reference to the transcription start site) of the gpIVORF (ORF67) was excised from the BamHI $\mathrm{K}$ fragment $(10,28)$ after being digested with BamHI and $A c c$ I. The ends of this fragment were blunted by filling in with Klenow enzyme before $B g l$ II linkers were added. This was then ligated into the $B g l$ II site of pCAT3M (kindly provided by G. Khoury, National Institutes of Health, Bethesda, Md.). In the resultant construct, pgpIVCAT, the CAT gene is under the transcriptional control of the gpIVORF promoter. In constructing pgpVCAT, the segment extending from +37 to -541 (with reference to the transcription start site) of gpVORF (ORF14) was excised from the $E c o$ RI $P$ fragment $(28,38)$ after being digested with $B s t$ NI and EcoRI. The resultant fragment was blunted by filling in with Klenow enzyme. After BglII linkers were added, this fragment was ligated into the BglII site of pCAT3M. The fusion joints of all of the VZV promoter-CAT constructs were verified by DNA sequencing. The pTKCAT that contains the VZV thymidine kinase promoter-CAT fusion has been described previously (18).

The plasmid pCMV4 was created by cutting pGORF4 with $N c o I$ and BamHI (the NcoI end was filled in with T4 DNA polymerase) to generate a $2.1-\mathrm{kb}$ fragment with the coding region of ORF4. This fragment was ligated to pG310 containing the IE gene I (IE-I) promoter of human cytomegalovirus (HCMV) (kindly provided by E. Mocarski, Stanford University, Palo Alto, Calif.) that had been digested with EcoRI and Bam HI (the EcoRI end was filled in with T4 DNA polymerase). In the resultant construct, pCMV4, the coding region of ORF4 was placed under the control of the strong IE promoter of HCMV.

To create pCMV62, the EcoRI E fragment $(28,38)$ was digested with $S c a I$ and $B g l \mathrm{II}$. A 5.0-kb fragment containing the entire coding region of ORF62 was isolated by gel electrophoresis. This fragment was ligated with pG310 that had been digested with EcoRI (subsequently blunted with mung bean nuclease) and Bam HI. In the resultant construct, pCMV62, the coding region of ORF62 was placed under the control of the strong IE promoter of HCMV. In all of the chimeric constructs generated, the orientation and the integrity of the fusion joints were verified by DNA sequencing.

The pCMV61 construct containing the coding region of ORF61 placed under the control of the IE promoter of HCMV was generously provided by $P$. R. Kinchington, The Eye and Ear Institute, University of Pittsburgh, Pittsburgh, $\mathrm{Pa}$.

DNA transfections. In transient transfection assays, routinely $5 \mu \mathrm{g}$ of target construct DNA and $5 \mu \mathrm{g}$ of effector construct DNA were used, unless indicated otherwise. In each transfection experiment, the total DNA amount was kept constant at $20 \mu \mathrm{g}$ by adding pBS plasmid (Stratagene) DNA as a carrier. For electroporations, A3.01 cells were washed twice with serum-free RPMI and resuspended in the same medium without serum, glutamine, or antibiotics at a density of $3 \times 10^{7}$ cells per $\mathrm{ml}$. Aliquots $(0.5 \mathrm{ml}$ each) of the cell suspension were mixed with plasmid DNA in an electroporation chamber and incubated on ice for $10 \mathrm{~min}$. The cells were then electroporated with two pulses by using a Progenitor II electroporator (Hoefer Scientific Instruments) with the settings at $200 \mathrm{~V}, 760 \mu \mathrm{F}$, and $10 \mathrm{~ms}$. The cells were incubated on ice for a further $15 \mathrm{~min}$ after pulsing. After $1 \mathrm{ml}$ of growth medium had been added, the cells were then transferred into 24-well tissue culture plates and were grown for $48 \mathrm{~h}$ before being harvested. Vero cells were transfected with DNA by using lipofectin (BRL Life Technologies, Inc.) in accordance with the manufacturer's instructions.

DNA sequencing. $\mathrm{CsCl}$ density gradient-purified plasmid DNA was sequenced with the Sequenase DNA sequencing kit (U.S. Biochemical Corp.) according to published procedures (32).

CAT assays. Cells were harvested $48 \mathrm{~h}$ after DNA transfections, and CAT assays were done essentially as described by Gorman et al. (15). The cells were washed once with phosphate-buffered saline and resuspended in $0.25 \mathrm{M}$ Tris $\mathrm{HCl}(\mathrm{pH} 7.8)$ and disrupted by three cycles of freezethawing. Protein concentrations in cell lysates were determined by using the Bio-Rad protein determination kit, according to the manufacturer's instructions. The CAT activity was assayed by using the same amount of total protein for all samples in an individual experiment. In certain experiments, samples displaying extremely high levels of CAT activity were repeated after appropriate dilutions of the samples had been made, such that the linear range of the assay was maintained. The CAT activity was quantitated with a Phos- 


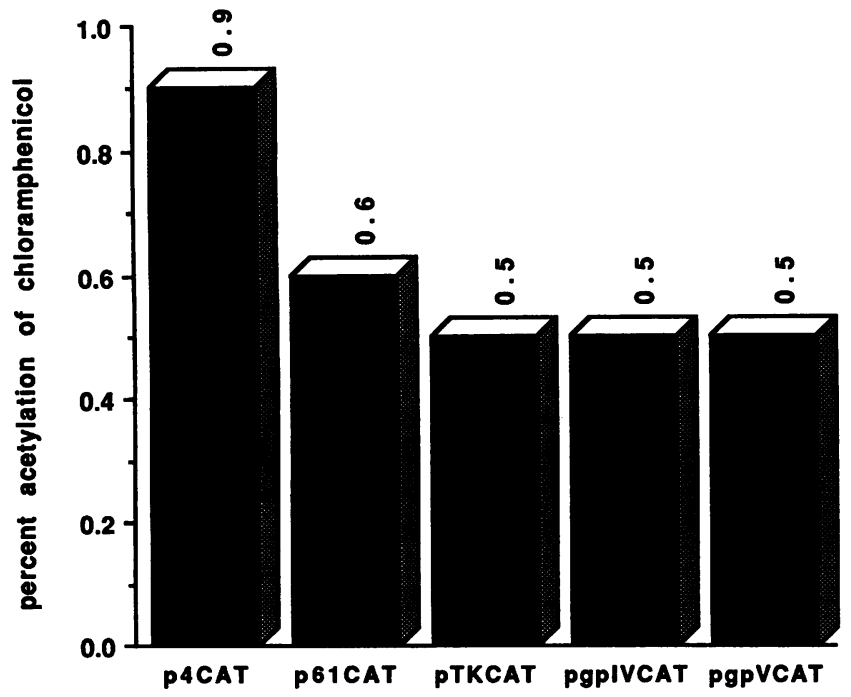

FIG. 1. Basal promoter activity of VZV genes of different kinetic classes. A3.01 cells were electroporated with $5 \mu \mathrm{g}$ of the indicated plasmid DNAs as described in Materials and Methods. The cells were harvested $48 \mathrm{~h}$ after electroporation, and the level of CAT activity in the cell lysates was assayed by using the same amount of total protein for all of the samples. The CAT activity was quantitated with a PhosphorImager scanner with Image Quant software from Molecular Dynamics.

phorImager scanner with Image Quant software from Molecular Dynamics (Sunnyvale, Calif.). All experiments were repeated at least three times with independent DNA transfections.

\section{RESULTS}

Basal promoter activity of $\mathrm{VZV}$ genes of different kinetic classes. The five promoters evaluated in the present study were selected to represent the three putative kinetic classes of VZV genes. ORF4 and ORF61 are putative IE $(\alpha)$ genes, while the thymidine kinase gene (tk) is a putative early $(\beta)$ gene. The two structural genes, glycoprotein IV (gpIV) and glycoprotein V (gpV), are putative late $(\gamma) \mathrm{VZV}$ genes. The levels of basal promoter activities of all of the VZV genes representing different kinetic classes used in the present study were very low in A3.01 cells. As shown in Fig. 1, the acetylation of $\left[{ }^{14} \mathrm{C}\right]$ chloramphenicol was less than $1 \%$ for all of the VZV promoter-CAT chimerae tested, whereas a control construct with the human immunodeficiency virus long terminal repeat promoter fused to CAT demonstrated $15 \%$ acetylation (data not shown). This indicates that the low level of basal activity elicited by the VZV promoters was due not to poor transfectibility of the A3.01 cells but rather to poor VZV promoter activity.

Modulation of VZV gene promoters by the gene product of ORF62 of VZV. In cotransfection experiments, the pGi26 plasmid (ORF62 driven from the cognate promoter) transactivated representative gene promoters of putative IE $(\alpha)$ and early $(\beta)$ kinetic classes. As shown in Table 1 , a 9.2-fold induction was seen with p4CAT, whereas a 32-fold induction above the basal level was elicited with p61CAT. The pTKCAT, representing a putative early $(\beta)$ gene of VZV, demonstrated a 38.8-fold induction above the basal level of expression with pGi26. pgpIVCAT and pgpVCAT, representing promoters of the late $(\gamma)$ kinetic class genes, were not
TABLE 1. Modulation of VZV gene promoters by the cognate promoter-driven ORF4, ORF61, and ORF62 in human T lymphocyte cell line A3.01

\begin{tabular}{|c|c|c|c|}
\hline $\begin{array}{c}\text { Target } \\
\text { construct }\end{array}$ & $\begin{array}{l}\text { Putative } \\
\text { kinetic class } \\
\text { of the target }\end{array}$ & $\begin{array}{l}\text { Effector construct(s) used } \\
\text { in cotransfection }{ }^{a}\end{array}$ & $\begin{array}{l}\text { Fold } \\
\text { induc- } \\
\text { tion }^{b}\end{array}$ \\
\hline \multirow[t]{6}{*}{ p4CAT } & IE & pGi26 & 9.2 \\
\hline & & pGORF4 & NI \\
\hline & & pGi26+pGORF4 & 44 \\
\hline & & pGi26+pGORF61 & 59.4 \\
\hline & & pGORF4+pGORF61 & NI \\
\hline & & pGi26+pGORF4+PGORF61 & 102.8 \\
\hline \multirow[t]{6}{*}{ p61CAT } & IE & pGi26 & 32.0 \\
\hline & & pGORF4 & NI \\
\hline & & pGi26+pGORF4 & 96.0 \\
\hline & & pGi26+pGORF61 & 91 \\
\hline & & pGORF4+pGORF61 & N \\
\hline & & pGi26+pGORF4+pGORF61 & 137 \\
\hline \multirow[t]{6}{*}{ pTKCAT } & Early & pGi26 & 38 \\
\hline & & pGORF4 & 2 \\
\hline & & pGi26+pGORF4 & 95 \\
\hline & & pGi26+pGORF61 & \\
\hline & & pGORF4+pGORF61 & \\
\hline & & pGi26+pGORF4+pGORF61 & 157.0 \\
\hline \multirow[t]{6}{*}{ pgpIVCAT } & Late & pGi26 & NI \\
\hline & & pGORF4 & NI \\
\hline & & pGi26+pGORF4 & \\
\hline & & pGi26+pGORF61 & NI \\
\hline & & pGORF4+pGORF61 & NI \\
\hline & & pGi26+pGORF4+pGORF61 & \\
\hline \multirow{6}{*}{ pgpVCAT } & Late & pGi26 & NI \\
\hline & & pGORF4 & NI \\
\hline & & pGi26+PGORF4 & NI \\
\hline & & pGi26+pGORF61 & NI \\
\hline & & pGORF4+pGORF61 & NI \\
\hline & & pGi26+pGORF4+pGORF61 & NI \\
\hline
\end{tabular}

${ }^{a}$ A3.01 cells were electroporated as described in Materials and Methods The target and effector constructs were used in 5- $\mu \mathrm{g}$ amounts in cotransfection experiments. In each cotransfection experiment, the total DNA amount was kept constant at $20 \mu \mathrm{g}$ by adding pBS plasmid (Stratagene) DNA as a carrier.

$b$ The fold inductions were calculated as described in the legend to Fig. 2 and are the means of triplicate transfections done in parallel. Standard deviations ranged from 6 to $36 \%$. NI, no detectable induction.

transactivated above basal-level expression. When pCMV62 (ORF62 driven from the IE promoter of HCMV) was used in the cotransfection experiments, a similar trend of transactivation was seen (Table 2). However, it should be noted that the expression of ORF62 by the strong HCMV IE promoter resulted in an 18.3-fold increase in expression of p4CAT above that seen with pGi26 (compare Tables 1 and 2), whereas the pTKCAT expression was increased by only 3-fold with pCMV62 above that seen with pGi26. Interestingly, the p61CAT did not show any increase with pCMV62 above that seen with pGi26, indicating a possible saturation phenomenon (compare Tables 1 and 2). It is likely that the enhanced activation of the target constructs with pCMV62 occurs as a result of enhanced expression of IE62 from the strong constitutive HCMV IE promoter. If this were the case, then increasing the effector DNA in cotransfections with the targets should lead to increased activation of the responsive targets. To test this possibility, we used pTK CAT as a representative responsive target to perform a series of cotransfections varying the amounts of effector DNA (pGi26) with a fixed amount of target DNA. As shown in Fig. 2, there was a dose-dependent activation of the pTKCAT target. In addition, pgpIVCAT, representing a late 
TABLE 2. Modulation of VZV gene promoters by the HCMV IE promoter-driven ORF4 and ORF62

\begin{tabular}{llc}
\hline $\begin{array}{c}\text { Target } \\
\text { construct }\end{array}$ & $\begin{array}{c}\text { Effector construct(s) used } \\
\text { in cotransfection }^{a}\end{array}$ & $\begin{array}{c}\text { Fold } \\
\text { induction }^{b}\end{array}$ \\
\hline p4CAT & pCMV62 & 168.8 \\
& pCMV4 & NI \\
p61CAT & pCMV62+pCMV4 & 752.0 \\
& pCMV62 & 24.0 \\
pTKCAT & pCMV4 & NI \\
& pCMV62+pCMV4 & 119.0 \\
pgpIVCAT & pCMV62 & 125.0 \\
& pCMV62+pCMV4 & 23.0 \\
pgpVCAT & pCMV62 & 238.0 \\
& pCMV4 & 1.9 \\
& pCMV62+pCMV4 & NI \\
& pCMV62 & 13.3 \\
& pCMV4 & NI \\
& pCMV62+pCMV4 & NI \\
\hline
\end{tabular}

${ }^{a}$ A3.01 cells were electroporated as described in Materials and Methods. The target and effector constructs were used in 5- $\mu \mathrm{g}$ amounts in cotransfection experiments. In each cotransfection experiment, the total DNA amount was kept constant at $20 \mu \mathrm{g}$ by adding pBS plasmid (Stratagene) DNA as a carrier.

${ }^{b}$ The fold inductions were calculated as described in the legend to Fig. 2 and are the means of triplicate transfections done in parallel. Standard deviations ranged from 3.7 to $29.4 \%$. NI, no detectable induction.

$(\gamma)$ gene promoter, showed slight (approximately twofold) activation with pCMV62, although no demonstrable activation was seen with pGi26 (compare Tables 1 and 2). However, no activation of the $\mathrm{gpV}$ promoter was seen within the limits of sensitivity of the assay. To examine the possibility that the lack of demonstrable activation of the late $(\gamma)$ gene promoters by IE62 may be due to limitations in the sensitiv-

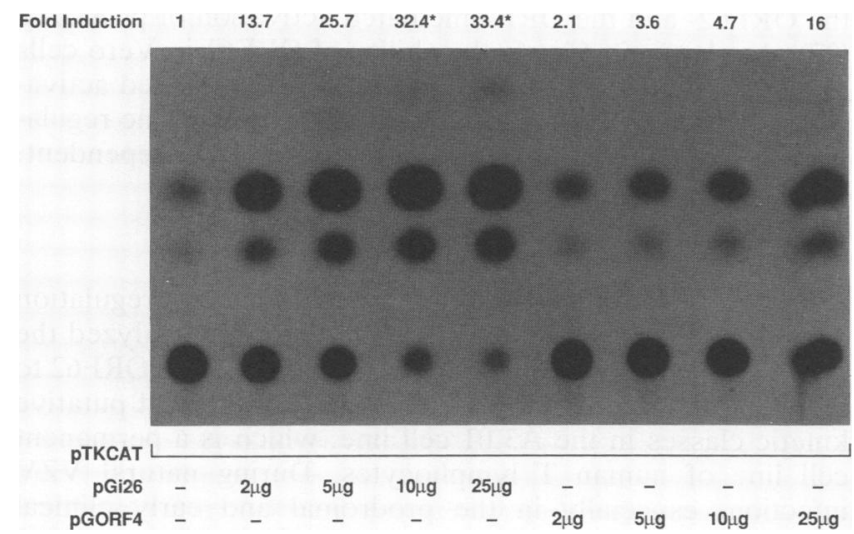

FIG. 2. Dose-dependent activation of pTKCAT by pGi26 and pGORF4. A3.01 cells were transfected with a fixed amount $(5 \mu \mathrm{g})$ of pTKCAT DNA and the indicated amounts of either pGi26 or pGORF4 by electroporation. The level of CAT activity was measured as indicated in the legend to Fig. 1. The fold induction of the CAT activity was calculated relative to the control experiment in which pTKCAT was transfected with $15 \mu \mathrm{g}$ of pBS carrier DNA. The value was set equal to 1.0 in the control experiment, and the fold inductions relative to the control experiment are given. It should be noted that when 10 or $25 \mu \mathrm{g}$ of pGi26 was used in cotransfections, the level of CAT activity of the cell extracts normalized for total protein content was over and above the linear range of the assay, as indicated by an asterisk. However, when these two samples were reassayed after diluting, the fold inductions were 61.2 and 118.3 , respectively.

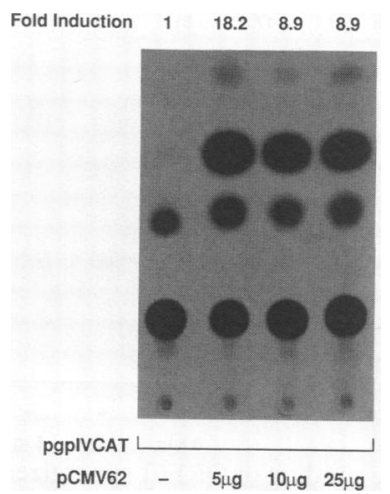

FIG. 3. Activation of a putative late $(\gamma)$ gene promoter by IE62. A3.01 cells were transfected with pgpIVCAT $(25 \mu \mathrm{g}$ of DNA) and the indicated amounts of pCMV62 (ORF62 driven from the HCMV IE promoter) by electroporation. The level of CAT activity was measured as indicated in the legend to Fig. 1. The fold inductions were calculated as described in the legend to Fig. 2. In the control experiment, pgpIVCAT was transfected with $25 \mu \mathrm{g}$ of pBS carrier DNA. Note that at higher effector concentrations, there is a diminution in activation. The reason for this diminution is not clear but may be due to detrimental effects on cellular transcriptional machinery when IE62 is overexpressed.

ity of the assay, cotransfections with greater amounts of target DNA ( 25 instead of $5 \mu \mathrm{g})$ and various amounts of pCMV62 were done. Under these conditions, IE62 was able to induce demonstrable activation of pgpIVCAT (Fig. 3). However, the $\mathrm{gpV}$ promoter still remained refractory to IE62 (data not shown). Thus, these findings demonstrate the ability of the ORF62 gene product to activate specific VZV genes of all three putative kinetic classes.

Modulation of VZV gene promoters by the gene product of ORF4 of VZV. The ability of the ORF4 gene product to activate VZV genes of different putative kinetic classes was assessed with constructs that expressed ORF4 either from its cognate promoter (pGORF4) or from the strong IE promoter of HCMV (pCMV4) in cotransfection experiments. As shown in Tables 1 and 2, the only VZV gene promoter-CAT chimera to be activated by the gene product of ORF4 was pTKCAT. The cognate promoter-driven ORF4 elicited a level of induction 2.6-fold above the basal level of expression. However, when the effector (pGORF4) DNA amount was increased in the cotransfections with pTKCAT, a dose-dependent increase in the activation of the pTKCAT was seen (Fig. 2). In addition, when the pCMV4 construct was used as the effector, a 23-fold induction of pTKCAT was seen (Table 2). Thus, it appears that the thymidine kinase promoter responds to the gene product of ORF4 in a concentration-dependent manner. In addition, these results suggest that the direct activation of VZV genes by the gene product of ORF4 may be limited to the putative early $(\beta)$ genes of VZV.

Synergistic activation of VZV genes by the gene products of ORF4 and ORF62. When pGi26 and pGORF4 were used in combination as effectors in the cotransfection experiments, there was synergistic activation of VZV genes of all three putative kinetic classes (Table 1). With p4CAT, the combination of pGORF4 and pGi26 elicited an induction that was 4.7-fold higher than what was seen with pGi26 alone. With p61CAT, the combination of pGORF4 and pGi26 elicited an induction that was threefold higher than that with pGi26 alone. With pTKCAT, the combination of PGORF4 and 


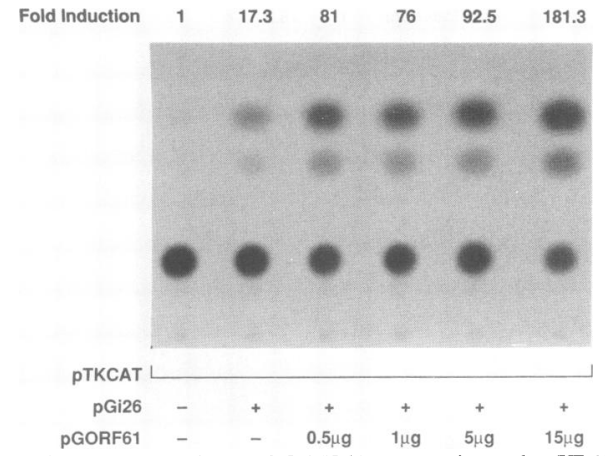

FIG. 4. The gene product of ORF61 synergizes the IE62-induced activation of pTKCAT. A3.01 cells were transfected by electroporation with a combination of pTKCAT, pGi26, and pGORF61 as indicated. In all cotransfections, $3 \mu \mathrm{g}$ of pTKCAT DNA was used. A fixed amount $(3 \mu \mathrm{g})$ of pGi26 was used in combinations containing this effector construct. The level of CAT activity was measured as described in the legend to Fig. 1. The fold inductions were calculated as described in the legend to Fig. 2. In the control experiment, $15 \mu \mathrm{g}$ of pBS carrier DNA was cotransfected with the pTKCAT.

pGi26 yielded an induction 2.5-fold above what was seen with pGi26 alone. Furthermore, the combination of pGi26 and pGORF4 was able to induce the expression of pgpIVCAT by a factor of 2 , whereas pGi26 alone was unable to activate the expression of pgpIVCAT. This activation was further augmented when pCMV62 and pCMV4 were used in combination as effectors in the cotransfection experiments instead of pGi26 and pGORF4 (compare Tables 1 and 2). However, the fold induction elicited by the combination over the pCMV62-induced activation closely paralleled the trend that was seen with the cognate promoter-driven ORF4 and ORF62. The enhancement of activation of p4CAT, p61CAT, and pTKCAT by the combination of pCMV62 and pCMV4 was 4.5-, 4.9-, and 1.9-fold, respectively. Nonetheless, a sevenfold enhancement of activation was seen with pgpIVCAT when both pCMV4 and pCMV62 were used in combination instead of pCMV62 alone in cotransfections performed with $5 \mu \mathrm{g}$ of target DNA (Table 2). Furthermore, pgpVCAT showed a 2.6-fold induction above the basal-level activity when both pCMV62 and pCMV4 were used in combination, whereas pCMV62 alone was unable to elicit any induction of pgpVCAT.

The effects of the ORF61 gene product on the expression of VZV genes. In cotransfection experiments, ORF61, whether expressed from the cognate promoter or from the strong IE promoter of HCMV, failed to transactivate directly the expression of any of the VZV gene promoter-CAT chimerae tested (data not shown). Nonetheless, in combination with pGi26, the pGORF61 (cognate promoter-driven ORF61) was able to synergize the activation of p4CAT, p61CAT, and pTKCAT (Table 1). Having established the ability of ORF61 to synergize the ORF62-mediated activation of VZV genes, we next examined whether the synergistic effect of ORF61 was dose dependent. As shown in Fig. 4, the synergistic effect of ORF61 on ORF62-mediated activation of pTKCAT did not appear to be linear with increasing amounts of pGORF61. In addition, pGORF61 was able to synergize the activation of pTKCAT by pGORF4, although the level of enhancement of activation was rather low (Table 1). Furthermore, when all three putative IE genes were used in combination as effectors in cotransfection experiments, the degree of activation of p4CAT, p61CAT, and pTKCAT was more

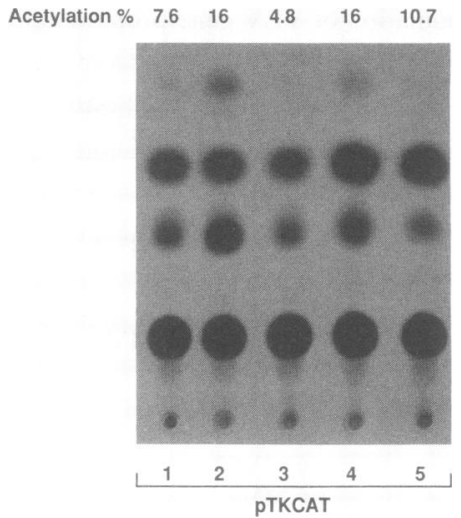

FIG. 5. The gene product of ORF61 represses the ORF62- and ORF4-induced activation of pTKCAT in Vero cells. Lanes: 1, Vero cells transfected with $10 \mu \mathrm{g}$ of pTKCAT and $20 \mu \mathrm{g}$ of pBS carrier DNA; 2, a combination consisting of $10 \mu \mathrm{g}$ of pTKCAT, $10 \mu \mathrm{g}$ of pGi26, and $10 \mu \mathrm{g}$ of pBS carrier DNA used for transfection; 3, a combination consisting of $10 \mu \mathrm{g}$ of pTKCAT, $10 \mu \mathrm{g}$ of pGi26, and 10 $\mu \mathrm{g}$ of pGORF61; 4 , a combination consisting of $10 \mu \mathrm{g}$ of pTKCAT, $10 \mu \mathrm{g}$ of pGORF4, and $10 \mu \mathrm{g}$ of pBS carrier DNA; 5, a combination consisting of $10 \mu \mathrm{g}$ of pTKCAT, $10 \mu \mathrm{g}$ of pGORF4, and $10 \mu \mathrm{g}$ of pGORF61. All transfections in Vero cells were performed by lipofection. The level of CAT activity was measured as described in the legend to Fig. 1. Values above the panel are the ratios of acetylated chloramphenicol to its unacetylated form, expressed as percentages. Note the relatively high level of basal expression of pTKCAT in Vero cells.

than that with pGi26 and pGORF4 together (Table 1). These findings indicate that the gene product of ORF61 is able to augment the transactivation ability of the gene products of ORF4 and ORF62 when coexpressed in human T lymphocytes. However, this is in contrast to the situation seen in Vero cells, in which ORF61 has been shown to repress both the ORF62- and the ORF4-mediated activation of pTKCAT (27). As shown in Fig. 5, the ability of ORF61 in Vero cells to repress both the ORF62- and the ORF4-mediated activation of pTKCAT was reconfirmed in this study. The regulatory role of ORF61 thus appears to be cell type dependent.

\section{DISCUSSION}

As part of a continuing study to understand the regulation of temporal gene expression in VZV, we have analyzed the ability of the gene products of ORF4, ORF61, and ORF62 to modulate the expression of VZV genes of different putative kinetic classes in the A3.01 cell line, which is a permanent cell line of human $T$ lymphocytes. During natural VZV infection, especially in the prodromal and early clinical phases, when virus actively replicates in the human host, VZV can be isolated from the peripheral blood mononuclear cells $(1,14,21,22,30,39)$. Of these peripheral blood mononuclear cells, predominantly $\mathrm{T}$ lymphocytes appear to be able to support VZV growth, thus implying an important role for $\mathrm{T}$ cells in VZV biology in vivo.

First, it is of interest to note that all of the VZV gene promoters used in the present study displayed very low-level basal activity in a lymphocytic-cell background (Fig. 1). This is consistent with reports from other investigators using a variety of different cell backgrounds for a number of VZV genes $(3,9,11,18,26,27)$.

The gene product of ORF62 was able to activate both ORF4 and ORF61 promoters. This is of special significance, 
since only these two VZV genes have been shown to have any modulatory activity on VZV gene expression in addition to that of ORF62. Furthermore, in contrast to ICP4 of HSV, which represses the expression of other IE genes (36), the VZV homolog, IE62, activates these putative IE genes of VZV. The ability of the ORF62 gene product to activate the thymidine kinase gene promoter (tk) and glycoprotein I (gpI) promoter in Vero cells has been previously reported (18). In the present study, we too were able to demonstrate the activation of the tk promoter by the ORF62 gene product in $T$ lymphocytes, indicating that the ORF62 gene product is capable of activating putative early $(\beta)$ gene promoters in a cell type-independent fashion. Of the two late $(\gamma)$ gene promoters tested, the gpIV promoter was clearly induced by IE62. However, the fact that larger amounts of target $(25$ versus $5 \mu \mathrm{g}$ of pgpIVCAT) were required to demonstrate substantial activation of pgpIVCAT (compare Tables 1 and 2 with Fig. 3) suggests inherently weak promoter activity of the gpIV gene in T lymphocytes.

Recently, Kinchington et al. (20) demonstrated the abundant presence of the ORF62 gene product in the virion tegument of VZV. Since the gene product of VZV ORF10 lacks any transactivator function $(6,26)$, unlike its HSV homolog, $\alpha$-trans-inducing factor (VP16 or Vmw65), which is a potent transactivator of $\operatorname{IE}(\alpha)$ genes of $\operatorname{HSV}(2,4,31$, $33)$, the incorporation of relatively large amounts of ORF62 gene product in the virion may be a compensatory mechanism to ensure rapid expression of IE $(\alpha)$ genes of VZV upon entry into a susceptible cell. This possibility is well illustrated by the findings of the present study, which clearly demonstrates the ability of the gene product of ORF62 to upregulate the expression of the other two putative IE $(\alpha)$ genes of VZV.

The gene product of ORF4 has been shown to transactivate the VZV tk gene promoter as well as the glycoprotein I (gpI) promoter of VZV in Vero cells (18). Although in these studies the level of gpI promoter activation was modest (twofold), in the present study the only gene promoter that was responsive to the gene product of ORF4 was the thymidine kinase (tk) promoter. Furthermore, we were not able to detect any autoregulatory activity of the ORF4 promoter when ORF4 was coexpressed either from the cognate promoter or from the IE promoter of HCMV with p4CAT. It would be interesting to evaluate other putative early $(\beta)$ genes of VZV such as ORF28 (the DNA polymerase gene) and ORF29 (the major DNA-binding protein) to determine whether the gene product of ORF4 is specifically capable of inducing only the early $(\beta)$ genes. However, it should be noted that although the ORF4 gene product by itself was not able to activate any VZV gene promoters other than the thymidine kinase promoter, it was capable of synergizing the transactivation of promoters of all kinetic classes induced by the gene product of ORF62 (Tables 1 and 2).

It is of interest to note that more potent activation of targets was seen when the gene products of ORF62 and ORF4 were expressed from the strong constitutive IE promoter of HCMV. Two likely explanations for this enhanced effect are (i) enhanced expression of the activator from the strong HCMV IE promoter and (ii) elimination of possible interference or feedback from the gene product onto the cognate promoter, thereby resulting in enhanced expression of the activator. However, the ability of pGi26 and pGORF4 to activate the targets in a concentration-dependent manner (Fig. 2) may argue against the latter possibility.

Unlike its HSV homolog ICP0, the gene product of ORF61 was not able to activate or suppress the expression of any of the VZV genes tested in the present study when expressed either from its cognate promoter or from the HCMV IE promoter (data not shown). Nonetheless, the fact that in the presence of the ORF61 gene product, both the ORF4 and the ORF62 gene products displayed enhanced activity (Tables 1 and 2; Fig. 4) supports the conclusion that the gene product of ORF61 plays a regulatory role in VZV gene expression. Cabirac et al. (3) observed a similar synergizing effect of the ORF61 gene product on the ORF62-mediated transactivation of the VZV tk promoter in CV-1 cells. However, Nagpal and Ostrove (27) recently demonstrated that the gene product of ORF61 actually was capable of repressing the transactivation induced by both ORF4 and ORF62 in Vero cells. In confirming the results of Nagpal and Ostrove we too observed a reduction in ORF4- or ORF62-mediated induction of the VZV tk promoter in the presence of the ORF61 gene product in Vero cells (Fig. 5). Thus, it appears that the gene product of ORF61 is able to act as an accessory transactivator or as a trans-repressor in a cell type-dependent manner in regulating the VZV gene expression. Although it is tempting to suggest that this unique cell type-dependent regulatory role of the ORF61 gene product may play a role in VZV latency and host range, further studies are needed to evaluate the regulatory role of the ORF61 gene product in neuronal cells as well as in other permissive cells, such as human foreskin fibroblasts, in modulating ORF62- and ORF4-induced VZV gene expression.

The fact that the glycoprotein $\mathrm{V}(\mathrm{gpV})$ promoter remained consistently refractory to activation by the ORF62 gene product was surprising. In vitro studies have clearly demonstrated an abundance of $\mathrm{gpV}$ protein as well as of its transcript in VZV-infected cells (23), indicating substantial transcriptional activity of this late $(\gamma)$ promoter during infection. Even when ORF4 and ORF61 were used in combination with ORF62, activation of $\mathrm{gpV}$ was minimal. Since the basal activity of the $\mathrm{gpV}$ promoter appears to be weak (Fig. 1 ), it is possible that the enhanced activity of the $\mathrm{gpV}$ promoter during VZV infection may be mediated by a virus-encoded transactivator protein(s) other than the gene product of ORF62, ORF4, or ORF61. Alternatively, it is possible that the construct pgpVCAT lacks critical cis elements essential for activation by the gene product of ORF62. We are in the process of investigating these possibilities.

In conclusion, we have demonstrated that the gene product of ORF62 is a major regulatory protein in VZV and is capable of activating VZV genes of all three putative kinetic classes. The gene products of ORF4 and ORF61 play an accessory regulatory role in synergizing the activation of VZV genes induced by the gene product of ORF62.

\section{ACKNOWLEDGMENTS}

We thank M. Sadeghi-Zadeh for constructing the pCMV62 plasmid and P. Ling for providing the pgpIVCAT and pgpVCAT constructs.

This work was supported by U.S. Public Health Service grants A118449 (W.T.R. and J.H. from NIAID) and 1R29-A124489 (J.D.M. from NIAID).

\section{REFERENCES}

1. Asano, Y., N. Itakura, Y. Kajita, S. Suga, T. Yoshikawa, T. Yazaki, T. Ozaki, K. Yamanishi, and M. Takahashi. 1989. Severity of viremia and clinical findings in children with varicella. J. Infect. Dis. 161:1095-1098.

2. Batterson, W., and B. Roizman. 1983. Characterization of herpes simplex virion-associated factor responsible for the induction of $\alpha$ genes. J. Virol. 46:371-377. 
3. Cabirac, G. E., R. Mahalingam, M. Wellish, and D. H. Gilden. 1990. Transactivation of viral tk promoters by proteins encoded by varicella zoster virus open reading frames 61 and 62 . Virus Res. 15:57-68.

4. Campbell, M. E. E., J. W. Palfreyman, and C. M. Preston. 1984. Identification of herpes simplex virus DNA sequence which encode a trans-acting polypeptide responsible for stimulation of immediate early transcription. J. Mol. Biol. 180:1-19.

5. Clements, J. B., R. J. Watson, and N. M. Wilkie. 1977. Temporal regulation of herpes simplex virus type I transcription: location of transcripts on the viral genome. Cell 12:275-285.

6. Davison, A. J. 1991. Varicella-zoster virus. J. Gen. Virol. 72:475-486.

7. Davison, A. J., and J. E. Scott. 1986. The complete DNA sequence of varicella-zoster virus. J. Gen. Virol. 67:1759-1816.

8. Disney, G. H., and R. D. Everett. 1990. A herpes simplex virus type I recombinant with both copies of the Vmw175 coding sequences replaced by the homologous varicella-zoster virus open reading frame. J. Gen. Virol. 71:2681-2689.

9. Disney, G. H., T. A. McKee, C. M. Preston, and R. D. Everett. 1990. The product of varicella-zoster virus gene 62 autoregulates its own promoter. J. Gen. Virol. 71:2999-3003.

10. Ecker, J. R., and R. W. Hyman. 1982. Varicella-zoster virus DNA exists as two isomers. Proc. Natl. Acad. Sci. USA 79:156-160.

11. Felser, J. M., P. R. Kinchington, G. I. Inchauspe, S. E. Straus, and J. M. Ostrove. 1988. Cell lines containing varicella-zoster virus open reading frame 62 and expressing the "IE" 175 protein complement ICP4 mutants of herpes simplex virus type I. J. Virol. 62:2076-2082.

12. Felser, J. M., S. E. Straus, and J. E. Ostrove. 1987. Varicellazoster virus complements herpes simplex virus type I temperature-sensitive mutants. J. Virol. 61:225-228.

13. Folks, T., S. Benn, A. Rabson, T. Theodore, M. D. Hoggan, M. Martin, M. Lightfoote, and K. Sell. 1985. Characterization of a continuous $\mathrm{T}$-cell line susceptible to the cytopathic effects of the acquired immunodeficiency syndrome (AIDS)-associated retrovirus. Proc. Natl. Acad. Sci. USA 82:4539-4543.

14. Gilden, D. H., A. R. Hayward, J. Krupp, M. Hunter-Laszlo, J. C. Hufi, and A. Vafai. 1987. Varicella-zoster virus infection of human mononuclear cells. Virus Res. 7:117-129.

15. Gorman, C. M., L. F. Mofiat, and B. H. Howard. 1982. Recombinant genomes which express chloramphenicol acetyl transferase in mammalian cells. Mol. Cell. Biol. 2:1044-1051.

16. Honess, R. W., and B. Roizman. 1974. Regulation of herpesvirus macromolecular synthesis. I. Cascade regulation of the synthesis of three groups of viral proteins. J. Virol. 14:8-19.

17. Honess, R. W., and B. Roizman. 1975. Regulation of herpesvirus macromolecular synthesis: sequential transition of polypeptide synthesis requires functional viral polypeptides. Proc. Natl. Acad. Sci. USA 72:1276-1280.

18. Inchauspe, G., S. Nagpal, and J. M. Ostrove. 1989. Mapping of two varicella-zoster virus encoded genes that activate the expression of viral early and late genes. Virology 173:700-709.

19. Inchauspe, G., and J. M. Ostrove. 1989. Differential regulation by varicella-zoster virus (VZV) and herpes simplex virus type I transactivating genes. Virology 173:710-714.

20. Kinchington, P. R., J. K. Hougland, A. M. Arvin, W. T. Ruyechan, and J. Hay. 1992. The varicella-zoster virus immediate early protein IE62 is a major component of virus particles. J. Virol. 66:359-366.

21. Koropchak, C. M., G. Graham, J. Palmer, M. Winsberg, S. F. Ting, M. Wallace, C. G. Prober, and A. M. Arvin. 1991.
Investigation of varicella-zoster virus infection by polymerase chain reaction in the immunocompetent host with acute varicella. J. Infect. Dis. 163:1016-1022.

22. Koropchak, C. M., S. M. Solem, P. S. Diaz, and A. M. Arvin. 1989. Investigation of varicella-zoster virus infection of lymphocytes by in situ hybridization. J. Virol. 63:2392-2395.

23. Ling, P., P. R. Kinchington, W. T. Ruyechan, and J. Hay. 1991. A detailed analysis of transcripts mapping to varicella-zoster virus gene 14 (glycoprotein V). Virology 184:625-635.

24. Maguire, H. F., and R. W. Hyman. 1986. Polyadenylated, cytoplasmic transcripts of varicella-zoster virus. Intervirology 26:181-191.

25. Maniatis, T., E. F. Fritsch, and J. Sambrook. 1989. Molecular cloning: a laboratory manual. Cold Spring Harbor Laboratory, Cold Spring Harbor, N.Y.

26. McKee, T. A., G. H. Disney, D. G. Everett, and C. M. Preston. 1990. Control of expression of the varicella-zoster virus major immediate early gene. J. Gen. Virol. 71:897-906.

27. Nagpal, S., and J. M. Ostrove. 1991. Characterization of a potent varicella-zoster virus encoded trans-repressor. J. Virol. 65:5289-5296.

28. Ostrove, J. M. 1990. Molecular biology of varicella-zoster virus. Adv. Virus Res. 38:45-98.

29. Ostrove, J. M., W. Reinhold, C. Fan, S. Zorn, J. Hay, and S. E. Straus. 1985. Transcription mapping of the varicella-zoster virus genome. J. Virol. 56:600-606.

30. Ozaki, T., T. Ichikawa, Y. Matsui, H. Kondo, T. Nagai, Y. Asano, K. Yamanishi, and M. Takahashi. 1986. Lymphocyteassociated viremia in varicella. J. Med. Virol. 19:249-253.

31. Pellett, P. E., J. L. C. McKnight, F. J. Jenkins, and B. Roizman. 1985. Nucleotide sequence and predicted amino acid sequence of a protein encoded in a small herpes simplex virus DNA fragment capable of trans-inducing $\alpha$ genes. Proc. Natl. Acad. Sci. USA 82:5870-5874.

31a.Perera, L. P. Personal observation.

32. Perera, L. P., J. E. Samuel, R. K. Holmes, and A. D. O'Brien. 1991. Identification of three amino acid residues in the $\mathbf{B}$ subunit of Shiga toxin and Shiga-like toxin II that are essential for holotoxin activity. J. Bacteriol. 173:1151-1160.

33. Post, L. E., S. Mackem, and B. Roizman. 1981. Regulation of $\alpha$ genes of herpes simplex virus: expression of chimeric genes produced by fusion of thymidine kinase with $\alpha$ gene promoters. Cell 24:555-565.

34. Post, L. E., and B. Roizman. 1981. A generalized technique for deletion of specific genes in large genomes: $\alpha$ gene 22 of herpes simplex virus I is not essential for growth. Cell 25:227-232.

35. Reinhold, W. C., S. E. Straus, and J. M. Ostrove. 1988. Directionality and further mapping of varicella-zoster virus transcripts. Virus Res. 9:249-261.

36. Roizman, B., and A. E. Sears. 1990. Herpes viruses and their replication, p. 1795-1841. In B. N. Fields and D. M. Knipe (ed.), Virology. Raven Press, Ltd., New York.

37. Shiraki, K., and R. W. Hyman. 1987. The immediate early proteins of varicella-zoster virus. Virology 156:423-426.

38. Straus, S. E., J. Owens, W. T. Ruyechan, H. E. Takifi, T. A. Casey, G. Vande Woude, and J. Hay. 1982. Molecular cloning and physical mapping of varicella-zoster virus DNA. Proc. Natl. Acad. Sci. USA 79:993-997.

39. Vonsover, A., S. Leventon-Kriss, A. Langer, Z. Smetana, R. Zaizov, D. Potaznick, I. J. Cohen, and T. Gotlieb-Stematsky. 1987. Detection of varicella-zoster virus in lymphocytes by DNA hybridization. J. Med. Virol. 21:57-66. 